LH/FSH-RH. This rise usually started on the second or third day, reached a maximum between the seventh and 11th days, and could be monitored every two or three days. For clinical purposes we therefore suggest sampling on days, $1,3,5,8$, and 11 of clomiphene administration, an $\mathrm{LH}$ rise of at least $3.5 \mathrm{U} / 1$ to a maximum above $6 \mathrm{U} / 1$ over this period indicating the integrity of the hypothalamo-pituitary-ovarian axis. Pregnanediol or other indirect indices of ovulation may be monitored also, but this is not essential.

The LH/FSH-RH test is thus useful in cases of suspected anovulation. An absent or impaired response implies an abnormality, primary or secondary, of the pituitary gonadotrophs, and if the situation is irreversible in such cases infertility may be treated with gonadotrophins provided there is biopsy evidence of adequate follicular tissue. ${ }^{10}$ With a normal or exaggerated LH-RH response it is important to carry out a clomiphene stimulation test also. In women with primary ovarian failure the exaggerated response to $\mathrm{LH} / \mathrm{FSH}-\mathrm{RH}$ is confirmed by high $\mathrm{LH}$ levels unaffected by clomiphene. Patients with normal LH/FSH-RH responses may be divided into those with disturbed cyclical gonadotrophin release, who respond to clomiphene, and those with a block in releasing-hormone production, who do not. Infertility in the former group may respond to repeated courses of clomiphene, with or without human chorionic gonadotrophin to induce follicular rupture. In the latter group $\mathrm{LH} / \mathrm{FSH}-\mathrm{RH}$ itself may eventually prove to be an effective and physiological alternative to gonadotrophin therapy.

We thank Dr. W. Bogie of Hoechst for supplies of LH/FSH-RH and Mr. A. Hyden for help with LH assay.

\section{References}

${ }^{1}$ Kastin, A. J., et al., fournal of Clinical Endocrinology and Metabolism, $1972,34,753$.

${ }^{2}$ Mortimer, C. H., et al., British Medical fournal, 1973, 4, 73.

3 Jacobson, A., Marshall, J. R., and Ross, G. T., American fournal of Obstetrics and Gynecology, 1968, 101, 1025.

4 Jacobson, A., et al., American fournal of Obstetrics and Gynecology, 1968, $102,284$.

5 Besser, G. M., et al., British Medical fournal, 1972, 3, 267.

6 Brooks, R. V., Gas Liquid Chromatography of Steroids, p. 147. Cambridge, Cambridge University Press, 1967.

7 Spitz, I. M., et al., New England fournal of Medicine, 1974, 290, 10.

${ }^{8}$ Mecklenburg, R. S., et al., Medicine, 1974, 53, 147.

${ }^{9}$ Marshall, J. C., and Russell Fraser, T., British Medical fournal, 1971, 4, 590.

${ }^{10}$ Sykes, D. W., and Ginsburg, J., American fournal of Obstetrics and Gynecslogy, 1972, 112, 408.

\title{
Evidence for HL-A-linked Genes in "Juvenile" Diabetes Mellitus
}

\author{
A. G. CUDWORTH, J. C. WOODROW
}

British Medical fournal, 1975, 3, 133-135

\section{Summary}

HL-A typing of 150 patients who had developed diabetes mellitus by the age of 30 years showed a significant association with HL-A 8 and $W$ 15. The HL-A genotypes were determined in 17 families in which two or more siblings had this type of diabetes. The zygotic assortment of HL-A haplotypes was found to be significantly disturbed from the expected random pattern, with a reduction in the number of siblings showing no identical haplotypes and an appreciable increase in the number with both haplotypes identical. This appears to be most consistent with the presence of a gene or genes predisposing to this type of diabetes at a locus closely linked to the HL-A chromosomal loci. This locus appears to have a fundamental role in the susceptibility to juvenile diabetes.

\section{Introduction}

Any inquiry into the mechanisms underlying juvenile-onset diabetes mellitus must take into account the role of genetic determination. Analysis of the familial aggregation of the disorder suggests that this is complex and is consistent with polygenic inheritance. ${ }^{1}$ One of the loci involved may be in the HL-A chromosomal region. ${ }^{2-4}$ To throw further light on this we have studied 150 cases of juvenile-onset diabetes together with families containing two or more diabetic siblings. The aim of the family studies was to determine whether within families the

University Department of Medicine, Liverpool L69 3BX

A. G. CUDWORTH, M.D., M.R.C.P., Lecturer in Medicine

J. C. WOODROW, M.D., F.R.C.P., Reader in Medicine pattern of inheritance of HL-A haplotypes is relevant to the development of diabetes.

\section{Patients and Methods}

The 150 patients were attending hospital with insulin-dependent diabetes. In all cases the age at onset was 30 years or less, this cut-off point being selected arbitrarily to achieve reasonable homogeneity. For comparison 68 diabetics whose age at onset ranged from 31 to 80 years were also studied. A control population of 300 was made up of blood donors, members of staff, and students living in the same geographical area. HL-A typing was performed with a modified lymphocytotoxicity technique. ${ }^{5}$

In the juvenile-onset cases detailed family histories were taken, and when one or more siblings with juvenile-onset diabetes were thus ascertained they, together with the parents, were also HL-A typed. The aim was to determine whether in respect of the affected siblings one, both, or neither HL-A haplotypes were identical. Identity of the haplotype is used here to indicate that haplotypes in two siblings not only type the same but are present on identical chromosomes inherited from a parent. By typing the parents it was possible to determine this. When two siblings have a haplotype typing the same it is not possible to be certain that they are identical if one parent is homozygous for this haplotype. When there was uncertainty because one or both parents were dead the family was excluded from the analysis.

\section{Results}

As studies have shown positive associations of juvenile-onset diabetes with HL-A 8 and W $15^{2-4}$ only the data for these particular antigens are given. No definite association with any other HL-A antigen was found. Of the 150 juvenile-onset diabetics $74(49.3 \%)$ were positive for HL-A 8 compared with $93(31.0 \%)$ of the controls; this gives a relative risk $^{6}$ of $2.17\left(\chi^{2}=14.14 ; \mathrm{P}=0.023\right)$. In a report from Copenhagen on 69 diabetics whose age at onset was 30 years or less? the relative risk for this type of diabetes in patients positive for HL-A 8 was $2 \cdot 79$. When the two sets of data are combined the overall risk for 
the two series is $2.40\left(\chi^{2}=30 \cdot 76 ; 1\right.$ D.F.), there being no evidence of heterogeneity between the two centres. In our study $31(20.7 \%)$ of the juvenile-onset diabetics were positive for W 15 compared with 30 $(10 \%)$ of the controls. This gives a relative risk of $2.35\left(\chi^{2}=9 \cdot 71\right.$; $\mathbf{P}=0.0037)$. The relative risk for the Copenhagen series was 1.87 , giving a combined relative risk of $2.09\left(\chi^{2}=14.35 ; 1\right.$ D.F.), with no evidence of heterogeneity. Eleven of our juvenile-onset diabetics $(7 \cdot 3 \%)$ had both HL-A 8 and W 15 compared with five of the controls $(1.7 \%)$. The relative risk for people with both antigens is therefore $4.67\left(\chi^{2}=9.36\right)$. Thus there is a positive association between juvenileonset diabetes and HL-A 8 and W 15, and in people with both antigens the relative risks appear to be additive.

The incidences of HL-A 8 and W 15 in the 68 diabetics whose age at onset was greater than 30 years were $25(36.8 \%)$ and $7(10.3 \%)$ respectively, which did not differ significantly from the frequencies in the controls. The incidences of HL-A 8 and W 15 were examined in relation to the age at onset (table I). Interestingly, there was a relatively low incidence of W 15 in the diabetics whose age at onset was 5 years or less and in those in the 11-15-years interval. When the data for those whose age at onset was 16 years or more are combined, analysis gives: $\chi^{2}=12.78 ; 6$ D.F.; $\mathrm{P}<0.05$.

TABLE I-Frequency of $H L-A 8$ and $W 15$ in Relation to Age at Onset of Diabetes

\begin{tabular}{|c|c|c|c|c|}
\hline $\begin{array}{c}\text { Age at Onset } \\
\text { (Years) }\end{array}$ & HL-A 8 & W 15 & $\begin{array}{c}\text { No HL-A } 8 \\
\text { or W } 15\end{array}$ & $\begin{array}{l}\text { No. of } \\
\text { Cases }\end{array}$ \\
\hline $\begin{array}{l}0-5 \\
6-10 \\
11-15 \\
16-20 \\
21-25 \\
26-30\end{array}$ & $\begin{array}{r}7(43 \cdot 8 \%) \\
14(46 \cdot 7 \% \text { \% } \\
22(56 \cdot 4 \%) \\
5(27 \cdot 8 \%) \\
7(36 \cdot 8 \% \%) \\
8(47 \cdot 1 \%)\end{array}$ & $\begin{array}{l}0 \\
7(23 \cdot 3 \%) \\
3(7 \cdot 7 \%) \\
3(16 \cdot 7 \%) \\
4(21 \cdot 1 \%) \\
3(17 \cdot 7 \%)\end{array}$ & $\begin{array}{r}9(56.3 \%) \\
9(30.0 \%) \\
14(35.9 \%) \\
10(55.5 \%) \\
8(42.1 \%) \\
6(35.3 \%)\end{array}$ & $\begin{array}{l}16 \\
30 \\
39 \\
18 \\
19 \\
17\end{array}$ \\
\hline
\end{tabular}

Patients typed as HL-A 8 plus W 15 are excluded.

\section{FAMILY STUDIES}

Table II shows the genotypes of affected siblings in 17 families. Two other sibships are excluded because though their phenotypes were consistent with the identity of one haplotype the relevant parent was dead and thus the identity could not be established with certainty. Fifteen families contained two affected siblings. Of these, 10 had inherited identical HL-A haplotypes, four had inherited one identical haplotype (the other being different), and in one family the affected siblings had not inherited a common haplotype. Family 16 contained three affected siblings, two of whom had identical haplotypes including W 15, and one of these a haplotype including HL-A 8 in common with the third. In the family containing four affected siblings (family 17) one haplotype was identical in all four.

TABLE II-HL-A Genotypes of Affected Siblings in 17 Families

\begin{tabular}{|c|c|c|}
\hline Family & Sibling 1 & Sibling 2 \\
\hline $\begin{array}{r}1 \\
2 \\
3 \\
4 \\
5 \\
6 \\
7 \\
8 \\
9 \\
10 \\
11 \\
12 \\
13 \\
14 \\
15^{*}\end{array}$ & $\begin{array}{l}2,12 / 2,12 \\
\mathrm{~W} 28, \mathrm{~W} 18 /-, \mathrm{W} 10 \\
2,12 / 9,8 \\
2,7 / 9,14 \\
11, \mathrm{~W} 22 / 1,8 \\
-, \mathrm{W} 10 / 1,8 \\
3,7 / 3, \mathrm{~W} 10 \\
9,5 / 2, \mathrm{~W} 15 \\
2, \mathrm{~W} 10 / 10,8 \\
2, \mathrm{~W} 15 / 11, \mathrm{~W} 18 \\
\mathrm{~W} 28, \mathrm{~W} 22 / 9, \mathrm{~W} 18 \\
2, \mathrm{~W} 15 / 2, \mathrm{~W} 10 \\
2,8 / 11,7 \\
-, 12 /-, \mathrm{W} 18 \\
1,8 / 2,27\end{array}$ & 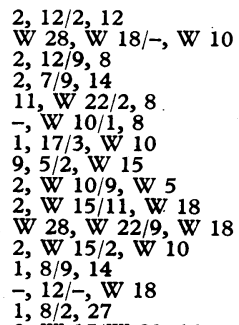 \\
\hline 16 & $\begin{array}{l}2, \mathrm{~W} 15 / 1,8 \\
\text { W } 29,12 / 1,8 \\
\text { (sibling No. 3) } \\
1,8 / \mathbb{W} 29,8 \\
2,12 / \mathrm{W} 29,8 \\
\text { (sibling No. 3) }\end{array}$ & $\begin{array}{l}\text { 2,W } 15 / W 32,14 \\
\begin{array}{l}1,8 / W 29,8 \\
2,12 / W 29,8 \\
\text { (sibling No. 4) }\end{array}\end{array}$ \\
\hline
\end{tabular}

*In this family the parent who contributed the 1, 8 haplotype was dead; the sibship is therefore scored as showing one identical haplotype.

The probabilities of two random siblings having both HL-A haplotypes identical, one haplotype identical, and neither haplotype identical are $P=0 \cdot 25, P=0 \cdot 5$, and $P=0 \cdot 25$, respectively. This assumes random zygotic assortment for HL-A haplotypes, which has been confirmed. ${ }^{8}$ The probability of obtaining the observed pattern of zygotic assortment in our study or in one more extreme is $P=0.001$.

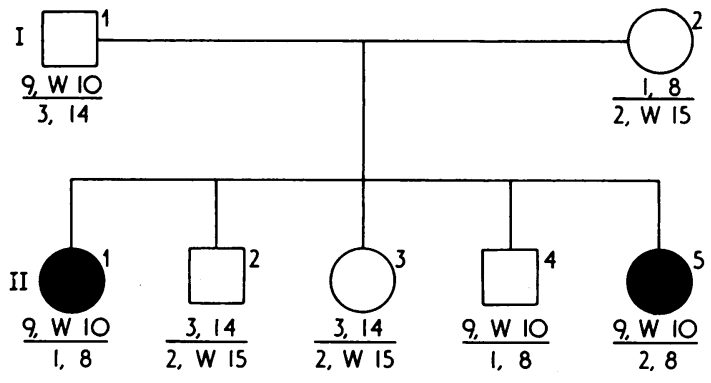

Family with two diabetic siblings showing cross-over between first and second HL-A loci.

\section{Discussion}

In this study the pattern of zygotic assortment of HL-A haplotypes in siblings with juvenile-onset diabetes differed significantly from that expected had the assortment been random. There was a reduction in the number of sibships in which the affected members had neither haplotype identical and an increase in those in which both were identical. It is unlikely that this was the result of the serologically defined HL-A genes themselves behaving as diabetogenic genes because the same pattern was seen in families in which HL-A antigens were present which are not increased in frequency in the general population of juvenile diabetics. These data seem most consistent with the presence on the HL-A chromosomes common to the affected members of a sibship of a diabetogenic gene closely linked to the HL-A loci. The diabetic population data suggest that this proposed diabetogenic gene is present about twice as frequently on HL-A chromosomes with alleles for HL-A 8 and W 15 than on other homologous chromosomes-that is, linkage disequilibrium. ${ }^{9}$

In families 13 and 16 there was no HL-A haplotype common to those affected. There are three possible explanations for this: (1) that there was a cross-over between the locus for the diabetogenic gene and the HL-A region, (2) that two different HL-A chromosomes with a diabetogenic gene were segregating in these families, and (3) that other genes outside the HL-A chromosomal region were involved in producing susceptibility to diabetes in these families.

One family, not included in the analysis, was of particular interest because a cross-over had occurred between the two HL-A loci in the maternal germ cell (see fig., subject II 5). The two affected siblings in this family thus had in common that part of the 1, 8 maternal chromosome which includes the second HL-A locus in addition to an HL-A chromosome from the father. If the shared part of the maternal chromosome contained a diabetogenic gene both siblings would have inherited it.

In the past 40 years almost every possible mode of inheritance has been postulated for diabetes mellitus. More recently the familial aggregation of diabetes has been re-analysed and considered to be more in keeping with polygenic inheritance. ${ }^{1}{ }_{10}$ Our study suggests that a locus in the HL-A chromosomal region constitutes a major component of the genotype of juvenile-onset diabetes. The fact that siblings of affected patients often inherit the same HL-A haplotypes but do not develop diabetes indicates two other sources of variability, both of which may be present. Firstly, other genes may be needed, interacting with the HL-Alinked gene, for the acquisition of the necessary threshold of susceptibility; and, secondly, environmental factors probably operate in susceptible people to initiate clinical disease.

One environmental factor for which circumstantial evidence has been obtained in juvenile-onset diabetes is viral infection. The pattern of seasonal incidence of the disease, the increased incidence of neutralizing antibodies to Coxsackie B4, and the ability of some viruses including Coxsackie B4 to produce $\beta$-cell damage support this hypothesis. ${ }^{11} \mathrm{Gamble}^{12}$ pointed out that there appears to be a relatively increased incidence of 
childhood diabetes in association with first attendance at school. Our data (table I) suggest that the relative frequencies of HL-A 8 and $\mathrm{W} 15$ vary according to age at onset. For example, the ratio between cases positive for HL-A 8 and those positive for W 15 in the 11-15 years age group was higher than with other age groups. This deserves more-detailed prospective investigation in combination with virological studies. If this variability is real a possible implication is that there are different alleles at the diabetogenic locus which interact with different viral agents. Thus one allele might be in linkage disequilibrium more with HL-A 8 and another with W 15.

If virus-mediated damage to pancreatic $\beta$-cells is important there are several possible ways in which genes in the HL-A chromosomal region might influence the outcome. Genes could exert their influence by affecting membrane virus receptor sites; by determining cross-antigenicity with viral antigens; or by determining the nature of the immune response to virus infection in a manner analogous to that shown for Ir genes in the $\mathrm{H}-2$ chromosomal region of mice. ${ }^{13}$ The mechanism of action of the proposed HL-A-linked diabetogenic gene, however, must remain speculative. The finding that a disproportionate number of sibships show the affected siblings to have both HL-A chromosomes identical implies that genes influencing susceptibility to diabetes are often inherited from both parents. If this is confirmed by a larger study it would follow that the gene action is such that the susceptibility is greater when two such genes are inherited than when only one is present.
We are indebted to Dr. S. Cope and Dr. M. M. Wood and other colleagues who have referred patients for study. Typing sera were kindly provided by the National Tissue Typing Reference Laboratory, Bristol, and the National Institute of Health, Bethesda, Md. Mr. N. Usher, Miss J. Anderson, Mrs. A. Dodd, Miss V. Moss, and Miss M. E. Wade provided excellent technical help. We are grateful to Dr. J. R. Green, of the department of computational and statistical science, University of Liverpool, for the analysis in the family study.

\section{References}

1 Simpson, N. E., Annals of Human Genetics, 1962, 26, 1.

2 Nerup, J., et al., Lancet, 1974, 2, 864.

3 Cudworth, A. G., and Woodrow, J. C., Lancet, 1974, 2, 1153.

4 Cudworth, A. G., and Woodrow, J. C., Diabetes, 1975, 24, 345.

5 Terasaki, P. I., and McClelland, J. D., Nature, 1964, 204, 998.

6 Woolf, B., Annals of Human Genetics, 1955, 19, 251.

7 Svejgaard, A., personal communication, 1974. (Breakdown of data given by Nerup et al. ${ }^{2}$ )

${ }^{8}$ Mattiuz, P. L., et al., Histocompatibility Testing. Copenhagen, Munksgaard, 1970.

${ }^{9}$ McDevitt, H. O., and Bodmer, W. F., Lancet, 1974, 1, 1269.

$10 \mathrm{Neel}$, J. V., et al., in Genetics and the Epidemiology of Chronic Diseases, ed. J. V. Neel, M. Shaw, and W. Schull, p. 105. United States Department of Health, Education and Welfare, Public Health Service, 1965.

11 Steinke, J., and Taylor, K. W., Diabetes, 1974, 23, 631.

12 Gamble, D. R., Postgraduate Medical fournal, 1974, 50, Suppl. No. 3, p. 538.

${ }^{13}$ Fogarty International Center Proceedings No. 15, Federation Proceedings, $1972,31,1087$.

\section{High Intestinal Lactase Concentrations in Adult Arabs in Saudi Arabia}

\section{G. C. COOK, M. T. AL-TORKI}

British Medical fournal, 1975, 3, 135-136

\section{Summary}

The maximum rise in blood glucose after $50 \mathrm{~g}$ lactose by mouth was determined in 40 adult Arabs. Out of 30 Bedouin, urban Saudi, and Yemeni and 9 of mixed ancestry (usually partly African), $25(83 \%)$ and $2(22 \%)$ respectively showed an increase of over $1.1 \mathrm{mmol} / 1$ $(20 \mathrm{mg} / 100 \mathrm{ml})$. In common with most northern Europeans and Hamitic people of northern Africa, Arabs in Saudi Arabia usually have high intestinal lactase concentrations in adult life. This persistence of high levels probably originated in the Arabian peninsula. Its selective advantage may have been associated with the fluid and calorie content of camels' milk, which is important for survival in desert nomads.

\section{Introduction}

Most northern Europeans and their descendants and the Hamitic people of northern Africa have high intestinal lactase concentrations in adult life. ${ }^{12}$ Other ethnic groups and all other mammalian species have low concentrations, this not being determined by environmental factors. ${ }^{1}$ Most adult Arabs ${ }^{3}{ }^{4}$ and Sephardic, oriental, and Ashkenazi Jews ${ }^{5}$ on the eastern Mediterranean littoral have low concentrations.

University of Riyadh, Saudi Arabia

G. C. COOK, M.D., F.R.C.P., Professor of Medicine

M. T. AL-TORKI, M.R.C.P., D.T.M.AND H., Assistant Professor of Medicine

\section{Patients and Methods}

The table summarizes the clinical details of 40 Arab inpatients at the King Abdul Aziz Hospital in Riyadh. They were admitted consecutively and agreed to be investigated after an explanation of the procedure. None had evidence of gastrointestinal disease, malnutrition, or diabetes mellitus. Designation of ethnic and national status was based on dialect, a detailed family history, and assessment of physical features including general appearance, stature, skin colour, hair distribution and appearance, and nasal contours. People with a mixed ethnic background are known locally as Khadiry (five of the nine in this study had distinct African characteristics). Fourteen patients had a $25-\mathrm{g} \mathrm{D}$-xylose absorption test; in 13, the 90 -minute blood xylose concentration was over $2.3 \mathrm{mmol} / 1(35 \mathrm{mg} / 100 \mathrm{ml})$ and the five-hour urinary excretion over $33.4 \mathrm{mmol}(5 \mathrm{~g})$.

After a 10-hour overnight fast, two capillary blood samples were taken in duplicate with a 10-minute interval. Lactose $50 \mathrm{~g}$ (Analar, B.D.H. ; glucose content of a $100 \mathrm{~g} / 1$ solution $<20 \mathrm{gm} / 1$ ) diluted in $500 \mathrm{ml}$ water was then given by mouth. Further capillary samples were taken, again in duplicate, at $15,30,60$, and 90 minutes. Blood glucose concentrations after immediate deproteinization were estimated in duplicate by a hexokinase method (Boehringer, Mannheim, 15931). Standard glucose curves were constructed for each series of determinations. Symptoms were sought during the following 24 hours.

\section{Results}

The maximum rise in blood glucose (table) usually occurred 30 or 60 minutes after lactose, but in nine and seven patients with a rise of more and less than $1.1 \mathrm{mmol} / 1(20 \mathrm{mg} / 100 \mathrm{ml})$ respectively, it occurred at 90 minutes. The rise of $9.7 \mathrm{mmol} / 1(176 \mathrm{mg} / 100 \mathrm{ml})$ in one of the Bedouin was associated with a fasting concentration of $4.8 \mathrm{mmol} / \mathrm{l}$ $(87 \mathrm{mg} / 100 \mathrm{ml})$. The mean fasting concentration of $6.8 \mathrm{mmol} / 1$ $(124 \mathrm{mg} / 100 \mathrm{ml})$ in one of the Khadiry was associated with previously undiagnosed diabetes mellitus. Four patients with a rise of less than $1.1 \mathrm{mmol} / 1$ responded normally to the xylose test; the one abnormal result was associated with a glucose rise of $5 \cdot 1 \mathrm{mmol} / 1(91 \mathrm{mg} / 100 \mathrm{ml})$. 